\title{
MEANS PRODUCED BY DISTANCES
}

\author{
Volker Diels-Grabsch* ${ }^{*}$, MowafFaQ HajJa \\ AND PANAGIOTIS T. KRASOPOUlOS
}

\begin{abstract}
We describe a methodology that can be used to construct new distances which produce many famous means. Its main application is to construct a distance for the logarithmic mean, settling an old open problem. We also use it to construct alternative distances for already known means, such as the arithmetic and all quasi-arithmetic means. Moreover, we show how to construct distances for almost all means that can be obtained from Cauchy's Mean Value Theorem, and apply this to construct distances for all Stolarsky means. Finally, we show how to construct a distance for a mean $\mathscr{M}_{q}(a, b)=q^{-1}(\mathscr{M}(q(a), q(b)))$, where $\mathscr{M}$ is another mean for which a distance is already known, and $q$ is a monotone bijection to a subinterval.
\end{abstract}

Mathematics subject classification (2010): 26A24, 26E60, 51K05.

Keywords and phrases: Distances, logarithmic mean, means, mean value theorem, quasi-arithmetic means, Stolarsky means.

\section{REFERENCES}

[1] R. Bhatia, The logarithmic mean, Resonance, 13 (2008), 583-594.

[2] I. BRUCE, The logarithmic mean, Math. Gaz., 81 (1997), 89-92.

[3] P. S. Bullen, Handbook of Means and Their Inequalities, Kluwer Academic Publishers, Dordrecht, 2003.

[4] B. C. CARLson, The logarithmic mean, Amer. Math. Monthly, 79 (1972), 615-618.

[5] E. L. DodD, The substitutive mean and certain subclasses of this general mean, Ann. Math. Statist., 11 (1940), 163-176.

[6] B. Ebanks, Looking for a few good means, Amer. Math. Monthly, 119 (2012), 658-669.

[7] M. HaJJA, Some elementary aspects of means, Int. J. Math. Math. Sci. (2013) Article ID 689560.

[8] G. H. Hardy, J. E. LitTlewood And G. Pólya, Inequalities, Cambridge University Press, Cambridge, 1934.

[9] J. Henderson (editor), Greek Mathematics I, translated by I. Thomas, Harvard University Press, Cambridge, 2006.

[10] G. Jameson And P. R. Mercer, The logarithmic mean revisited, Amer. Math. Monthly, 126 (2019), 641-645.

[11] A. Kolmogorov, Sur la notion de la moyenne, Atti Accad. Naz. Lincei Rend., 12 (1930), 388-391.

[12] E. B. Leach And M. C. Sholander, Extended mean values, Amer. Math. Monthly, 85 (1978), 84-90.

[13] D. H. Lehmer, On the compounding of certain means, J. Math. Anal. Appl., 36 (1971), 183-200.

[14] M. E. MAYs, Functions which parametrize means, Amer. Math. Monthly, 90 (1983), 677-683.

[15] P. R. Mercer, Cauchy's mean value theorem meets the logarithmic mean, Math. Gaz., 101 (2017), $108-115$.

[16] M. L. D'Ooge (editor and translator), Nichomachus of Gerasa: Introduction to Arithmetic, N. Y., 1926.

[17] K. B. Stolars Ky, Generalizations of the logarithmic mean, Math. Mag., 48 (1975), 87-92.

[18] ZH.-H. YANG Three families of two-parameter means constructed by trigonometric functions, J. Inequal. Appl. (2013) Article 541. 